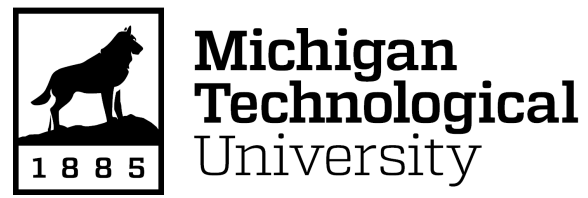

Michigan Technological University Digital Commons @ Michigan Tech

Dissertations, Master's Theses and Master's Reports

2018

\title{
ABOVE-GROUND BIOMASS AND CARBON ESTIMATIONS AND RECOMMENDATIONS FOR FORESTS IN TURKEY
}

Cuma Uykun

Michigan Technological University, cuykun@mtu.edu

Copyright 2018 Cuma Uykun

\section{Recommended Citation}

Uykun, Cuma, "ABOVE-GROUND BIOMASS AND CARBON ESTIMATIONS AND RECOMMENDATIONS FOR FORESTS IN TURKEY", Open Access Master's Thesis, Michigan Technological University, 2018.

https://doi.org/10.37099/mtu.dc.etdr/689

Follow this and additional works at: https://digitalcommons.mtu.edu/etdr

Part of the Forest Biology Commons, Forest Management Commons, and the Other Forestry and Forest Sciences Commons 


\title{
ABOVE-GROUND BIOMASS AND CARBON ESTIMATIONS AND RECOMMENDATIONS FOR FORESTS IN TURKEY
}

\author{
By \\ Cuma Uykun
}

\begin{abstract}
A THESIS
Submitted in partial fulfillment of the requirements for the degree of MASTER OF SCIENCE

In Forestry
\end{abstract}

MICHIGAN TECHNOLOGICAL UNIVERSITY

2018

(C) Cuma Uykun 
This thesis has been approved in partial fulfillment of the requirements for the Degree of MASTER OF SCIENCE in Forestry.

School of Forest Resources and Environmental Science

\author{
Thesis Advisor: $\quad$ Tara L. Bal \\ Committee Member: $\quad$ Andrew J. Storer \\ Committee Member: $\quad$ Yvette L. Dickinson
}

School Dean: Andrew J. Storer 


\section{Table of Contents}

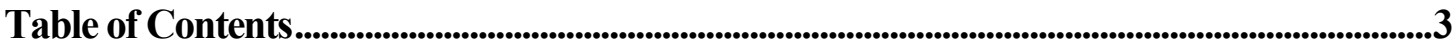

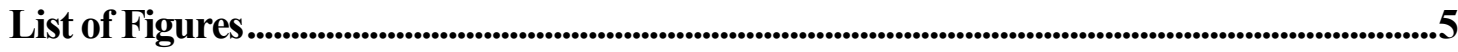

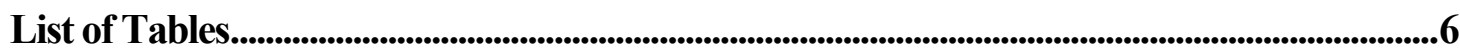

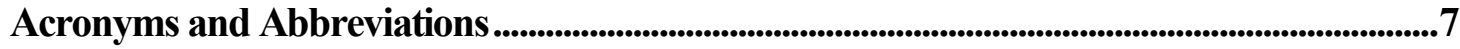

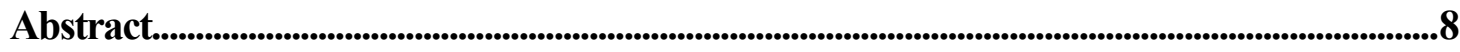

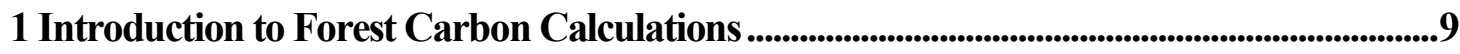

1.1 Forest Carbon Policy in Turkey …........................................................... 13

1.2 Biomass and Carbon Pools (CP) ................................................................ 16

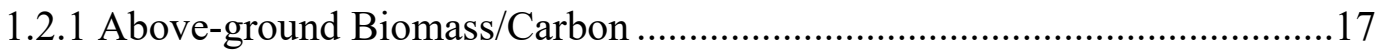

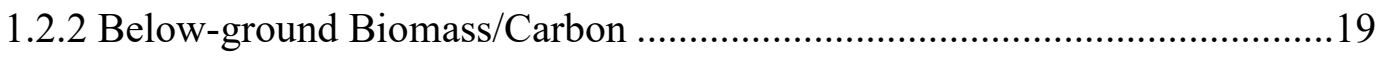

1.2.3 Dead Organic Matter and Litter.........................................................20

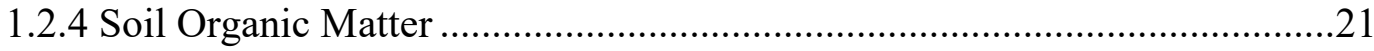

1.3 Gain and Loss Estimation Methods ..........................................................22

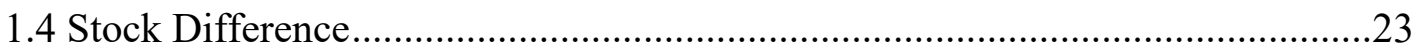

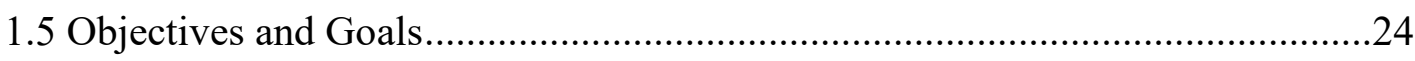

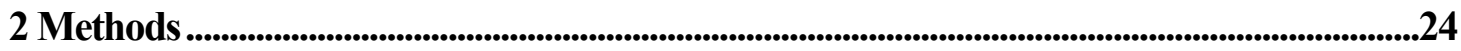

2.1 Data Collection and Site Description .......................................................24 
2.3 Data Preparation for allometric equations......................................................28

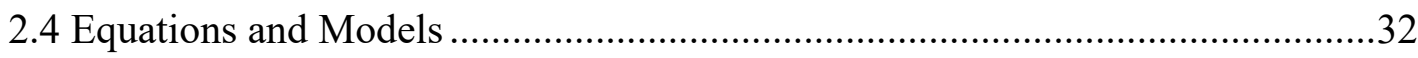

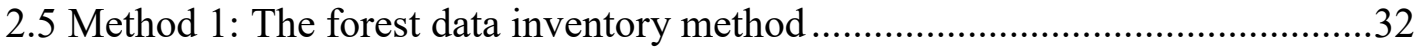

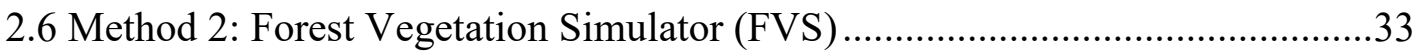

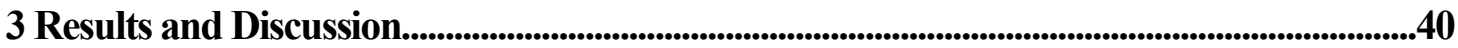

3.1 Recommendations for forests in Turkey ....................................................44

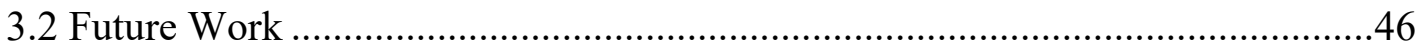

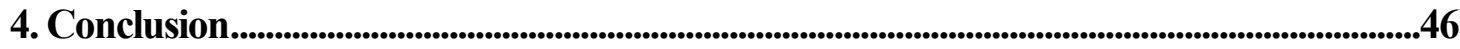

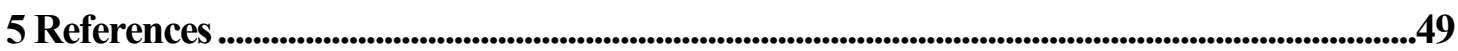

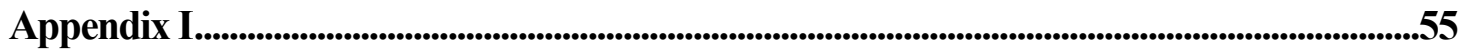




\section{List of Figures}

Figure 1: Forest Vegetation Simulator (FVS) data preparation steps; Data preparation $>$ Modify/Create Location $>$ "Edit Location File" $>$ Edit records that define Location Using Database (Type C) $>$ Location Name "Database"> Data Source "C/FVSData/Blank-Database.accd" 37

Figure 2: Forest Vegetation Simulator "CarbRept" keywords under Fire Fuel Extension (FFE) function, this tool is used to calculate above-ground carbon. Figure shows where this tool in FVS (Suppose v2.06, 2017). .38

Figure 3: Forest Vegetation Simulator model carbon results include multiple carbon pools (FVS-Output Jenkins Equations) above-ground carbon was measured with fiveyear intervals started in year 2016. Data used here is from Penobscot Experimental

Forest in Maine (2016) 39 


\section{List of Tables}

Table 1: Expected absorbed carbon stock differences between the years 2008-2020 in

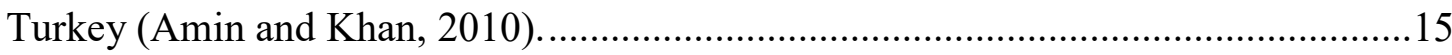

Table 2: Trees inventoried, their total biomass and mean diameter at breast height $(\mathrm{DBH})$ in Penobscot Experimental Forest (PEF) in Maine. Data was collected in summer 2016. Biomass (in tons) were calculated by using Jenkin`s equation for above ground biomass $\left(\mathrm{Bm}=\operatorname{Exp}\left(\mathrm{B}_{0}+\mathrm{B}_{1} \ln D B H\right)\right)$.

Table 3: Above-ground biomass species coefficient/parameters for species that measured for this study (Jenkins et al. 2003) 33

Table 4: Comparison between two methods of carbon calculations; Forest vegetation simulator modeling and data inventory method (manual allometric equation for each tree) based on their use and efficiency in order to make recommendation for carbon forest management in Turkey. 


\section{Acronyms and Abbreviations}

AGB: Above Ground Biomass

BGB: Below Ground Biomass

BEF: Biomass Expansion Factor

CG: Annual gain of carbon (carbon gain)

COP: Conference of Parties

CL: Annual loss of Carbon (carbon loss)

CP: Carbon Pool

DBH: Diameter at Breast Height

DOM: Dead Organic Matter

FVS: Forest Vegetation Simulator, Forest Service, (1973)

GHG: Greenhouse Gas

KP: Kyoto Protocol

LULUCF: Land Use, Land Use Change, and Forestry

LT: Litter

LIDAR: Light Detection and Ranging

IPCC: Intergovernmental Panel on Climate Change

SOM: Soil Organic Matter

SVS: Stand Visualization System

UNFCCC: United Nations Framework Convention on Climate Change 


\section{Abstract}

Climate change mitigation and biodiversity conservation are issues that are tightly related to the environment and the public's awareness of forest conservation, which are currently major areas of global interest. Greenhouse gas emissions and removals are required to be reported regularly (5 year intervals) and in compliance with the United Nation's Framework Convention on Climate Change (UNFCCC) of 1992, which was later extended by the Kyoto Protocol International Treaty. The UNFCCC`s policy has been accepted by more than 150 countries. Turkey`s forests are controlled and managed by the government and some major tree species still need to have their own equations developed across Turkey. This study reviews the use of current carbon estimation methods in Turkey (which are gain-loss and stock differences), how to create allometric equations and outlines the use of Forest Vegetation Simulator (FVS) as a modeling tool. Additionally, this study suggests methods for improving biomass and carbon calculations in Turkey. Manual calculations were compared with the FVS, and the numerical results were not significantly different, as expected as both used Jenkin`s formula and method. However, these two methods do differ on the basis of time efficiency, and field work intensity. Manual calculations are significantly slower than The FVS program. However, manual calculations are needed with field work to recollect data periodically that has changed over the time; such as diameter at breast height (DBH) or loses from harvesting or mortality. The discussions here will be a guide for future developing improved carbon calculations in Turkey. 


\section{Introduction to Forest Carbon Calculations}

Global warming and climate change have been some serious concerns for many countries over the last several decades. Forests play a vital role in reducing the amount of greenhouse gas emissions that are released from the atmosphere. Knowing the amount of stored carbon in forests is important, as it can help make better management prescriptions or update current prescriptions to increase the amount of stored carbon in forests. Forest management or land-use systems management can be an effective way managing and mitigating environmental changes such as global warming, climate change, and wildlife changes such as invasive species (Morote et al., 2012). Being aware of the biomass and carbon stocks in forests can provide forest managers and policy makers with essential information to determine land planning and forest management plans (Morote et al., 2012). This study only relates to forest management plans associated with carbon storage rather than other land-use systems. For instance, I do not include crop-land or agriculture areas in carbon levels while they absorb carbon. Above-ground carbon was measured as one of the major pools in the forest ecosystem. In this study, I will be focusing on general policy regarding "Biomass and Carbon Calculations in Forests" and I will be preparing recommendations for Turkey based on methods discussed in here. I used two methods, data inventory and forest vegetation simulator (FVS modeling) to calculate carbon in forests. A discussion includes the effects of forest management plans stored carbon on and how the best method can be applied to increase the amount of stored carbon in Turkey. 
As stated in the Kyoto Protocol of the United Nations Framework Convention on Climate Change (UNFCCC, 2007), industrial nations (Annex 1) were required to report their carbon budget by the year 2008 and continuously in five-year increments (Thenkabail et al., 2004). Carbon that has been stored in land consists of biomass and soil carbon pools. Foresters need to know the amount of biomass in order to estimate the stored carbon, which is frequently done in the United States using Forest Vegetation Simulator (FVS) or the data inventory method (manual inventory). "Biomass" in this treatment involves the above-ground (leaves, branches, boles) and below-ground biomass (roots), litter, deadwood and soil organic matter (Ravindranath and Ostwald, 2007). Currently, five carbon pools must be reported under the United Nations Framework Convention on Climate Change (UNFCCC) (Boisson de Chazournes 2008). Total carbon inventories are generally estimated and reported by two methods in most countries: "gain-loss" and "stock-difference" (Ravindranath and Ostwald, 2007). Countries are asked to develop, periodically update, and make available to the conference of parties (COP), their national inventories about emissions and removals of GHGs using comparable methods (i.e. Stock differences and gain-loss methods). Alterations to forests and land-use systems are significant sources of carbon and biomass production. Most countries use the two general methods to report their relative amounts of carbon and biomass every five years: "Stock Difference" and "Gain and Loss." These methods are accurate and upto-date. However, countries such as Turkey need to improve or create new methods because not all of the tree species in Turkey have individual tree coefficients in order 
to calculate individual tree biomass and carbon. The approaches for investigating carbon in forests under the Kyoto Protocol requirements allow more informed policy decisions that can lead to an increase in stored carbon and mitigate global warming (Lorenz and Lal 2010).

Biomass and carbon calculations are usually calculated together because carbon is stored in forest biomass and has a tight mathematical relationship. The amount of biomass is multiplied by 0.5 to get estimated carbon because $50 \%$ biomass is assumed as stored carbon in forests (IPCC, 2000). In general, the biomass and carbon (mass) in various pools were measured in the above-ground biomass (AGB), below-ground biomass (BGB), dead wood (DW), litter (L), and the soil organic matter (SOM). These protocols for sampling these individual components vary and can be calculated in different manners, depending on the agency or reporting country. In this study emphasis is on above ground biomass to be able to make an appropriate comparison between methodologies used in the same study site. Currently, Turkey uses two methods that are gain-loss and stock difference. These two methods measure general stored carbon without providing details such as which tree stores more carbon than others. There are also other protocols to estimate/calculate carbon stocks in forests, in addition to these two general methods. However, there are some limitations of these methods that need to be addressed, for example in one case, forest harvests were ignored in 2008 , but later inventories take these into account as removed carbon, so the actual numbers are difficult to compare over time (Downie et al. 2014). In addition, some of these methods using species specific allometric models have not 
been implemented or developed for all forested areas across the countries and tree species. For example, FVS as a modeling tool has 20 variants but it is only used for tree species within the United States. Therefore, the gain-loss and stock-difference methods are easier to use locally, are only somewhat precise, and are the two general methods that are requested for reporting levels of carbon so that they are comparable and applicable internationally (Federici, 2011).

The work presented here includes comparisons regarding more accurate carbon and biomass calculation methods and suggested steps that could be implemented in the country of Turkey. Included is:

1- A description of how to calculate the amount of carbon and biomass with a data inventory method (data inventory, field work, sample processing in laboratory)

2- A description of how to calculate biomass and carbon by Forest Vegetation Simulator (FVS) and GIS tools such as LIDAR (Light Detection and Ranging). In this study, FVS was used as the primary modeling tool for calculating carbon and biomass stored in forests. 3 - Direct comparison of data inventory methods and FVS with data from Maine, comparing model results and overall use and efficiency for time and labor 
4 - Recommendations to implement accurate carbon and biomass inventory and reporting to inform forest management planning in Turkey.

\subsection{Forest Carbon Policy in Turkey}

Ninety-nine percent of forests in Turkey belong to the government, which controls forest management plans and all forest processing across the country (Baskent, Köse, and Keles, 2011). The Turkish forest service is responsible for the entirety of forests in Turkey; the organization called 'Minister of Forest and Agriculture' which is the official organization in Turkey. Carbon calculations needed

to be improved, and new methods are required based on forest structure in Turkey and the desire to improve forest management plans to more efficiently manage stored carbon. Currently Turkey uses gain-loss and stock changes to estimate national carbon storage in forests. Additionally, there are some studies that were made on Turkey's species to create their coefficients (Tolunay, 2011). These studies were made seven years ago and need to be extended under the official forestry organization which I will be working as an official forester. The source of carbon in Turkey is in soil (including below-ground biomass) at about $74 \%$ with above ground biomass around $22 \%$. Other sources are dead wood and litter. Interest has increased in biomass and carbon calculations with changes of climatic conditions. It is now a more serious task to report carbon and biomass stocks in Turkey (Tolunay, 2011). 
Additionally, this study was prepared as a guideline for the future to create new equations for tree species in Turkey and improve carbon reporting. Forest carbon calculations in Turkey are currently made by following the Intergovernmental Panel on Climate Change (IPCC) requirements and gain-loss and stock difference methods. These methods produce adequate estimations for the total amount of carbon. However, these two methods calculate all carbon together, ignoring details about carbon pools or specific species. To investigate options for Turkey, Forest Vegetation Simulator (FVS) was used to calculate above ground carbon and the steps and efficiency were compared with manual field inventory calculations.

Common tree species in Turkey include Quercus spp (26.34\%), Pinus brutia (25.11\%), Pinus nigra (19\%), Fagus spp (8.5\%), Pinus silvestiris (6.80\%), and other species such as Picea spp, Abies spp, Poplar or Populus spp, Castanea spp ( Sonmez, 2015). Allometric equations were created in Turkey locally for conifers Pinus sylvestris L. (Uğurlu et al. 1976; Atmaca 2008; Çömez 2010; Tolunay 2010), Pinus brutia Ten. (Sun et al. 1980; Ünsal, 2007), Picea orientalis (L.) Link (Özkaya 2004), and Pinus nigra Arnold (Çakıl, 2008). Deciduous species equations were also made for Fagus orientalis Lipsky (Saraçoğlu 1998), Alnus glutinosa (L.) Gaertn. (Saraçoğlu, 2000), Quercus spp. (Durkaya, 1998), and Castanea sativa Mill. (İkinci, 2000). However, these equations are not met all over the Turkey because the data collected were or local or regionally based (Tolunay, 2011). As a result, there is a huge task to prepare new equations for tree species in Turkey across the country and potentially develop regional variants. 
After analyzing previous data in Turkey`s forests, some predictions were made about potentially absorbed carbon within years (Table 1) (Amin and Khan, 2010). Carbon trend on table 1 was predicted basis of analyzing previous carbon trends for example, the first official record is 12023,852 ton/year across the country in 1990 and the last record is 13970,634 ton/year in 2005. Stock differences years between 2008 and 2020 were predicted based on previous years` carbon trend (Amin and Khan, 2010). The calculation was made between the years 1990-2007 by following equations $\mathrm{C}=-292217+152,951 *$ (year) where $\mathrm{C}$ is carbon. The years 2008 2020 predictions were made with trend analysis technique (Amin and Khan, 2010). These are modeled predictions, with no species information so we need to have advance methods that we can measure carbon in detail such as species level.

Table 1: Expected absorbed carbon stock differences between the years 2008-2020 in Turkey (Amin and Khan, 2010).

\begin{tabular}{|c|c|}
\hline Years & $\begin{array}{c}\text { Expected absorbed } \\
\text { carbon (million/tons) }\end{array}$ \\
\hline 2008 & 14,909 \\
\hline 2009 & 15,062 \\
\hline 2010 & 15,215 \\
\hline 2011 & 15,367 \\
\hline 2012 & 15,520 \\
\hline 2013 & 15,673 \\
\hline 2014 & 15,826 \\
\hline 2015 & 15,979 \\
\hline 2016 & 16,132 \\
\hline 2017 & 16,285 \\
\hline 2018 & 16,438 \\
\hline 2019 & 16,591 \\
\hline 2020 & 16,744 \\
\hline
\end{tabular}


The National Green House Gas (GHG) emissions and removals are calculated by following revised 1996 IPCC guidelines (National Green House Gas Inventory Report, 2012) which are gain-loss and stock differences that explained in section 1.3 and 1.4. Absorbed carbon level has been increasing from 1990 (12,023 million/tons) to $2008-2020$ (14,909-16,744 million/tons). As a result of carbon policy in Turkey, this study was made to emphasize why Turkey should have individual tree equations instead of using stock differences and gain-loss method.

\subsection{Biomass and Carbon Pools (CP)}

There are five carbon pools in a forest ecosystem, the total equation for carbon pool calculations is $\mathrm{C}=\mathrm{AGB}+\mathrm{BGB}+\mathrm{DW}+\mathrm{LT}+\mathrm{SC}$ where, $\mathrm{C}$ is total carbon, $\mathrm{AGB}$ is above-ground biomass, BGB is below-ground biomass, DW is deadwood, LT is litter and SC is soil organic carbon (Ravindranath and Ostwald, 2007). These five aspects are measured by their specific methods explained in the following sections to determine the amount of carbon and biomass stock in a forest. Although, this study focuses on above ground biomass and carbon other pools are briefly described for integrity. These pools might be measured with their own model and methods that explained below. Turkey`s current reporting and estimation methods do not differentiate these different pools, which may have implications for carbon management. This is also why Turkey needs to have detailed methods to differentiate stored carbon in each pool. Carbon pools may store different percentages of stored carbon, percentages below show how much carbon stored in the U.S. forests by state and ownership group in 2014, where found to store the following percentages broken 
down by pools: Above ground (36.32\%), below ground ( $6.3 \%)$, soil (43.1\%), forest floor (7.16\%) (Smith, Heath, and Nichols, 2007).

\subsubsection{Above-ground Biomass/Carbon}

Above ground biomass refers to the total mass of biomass in live trees (such as stem, branches, leaves), brush and woody live plants above ground (Projects, 2015). This is the biggest pool that includes/stores the majority of carbon (Ravindranath and Ostwald, 2007). Forest biomass includes about $80 \%$ carbon (C) in all above ground plants (Peichl and Arain, 2007). Above-ground carbon and biomass are calculated by the following methods;

-harvest methods, data inventory method (destructively cut and measure all tree parts)

-carbon flux measurements, (gain-loss, stock-differences would be in this category)

-satellite/remote sensing, (models are generally still needed to calibrate aerial data)

-modeling, plot method (FVS would be in this category) (Ravindranath and Ostwald, 2007)

Although several methods may be available to estimate the above-ground carbon and biomass, this study was focused on the data inventory method (data inventory) and FVS model to estimate carbon storage and biomass in forests. All living vegetation including wood related parts; stems, stumps, barks, seeds, and 
foliage above the soil have above-ground carbon and biomass (Ravindranath and Ostwald, 2007). In order to calculate this, the sample plot and tree species must first be identified. Tree Diameter at Breast Height (DBH) and Height (HT) are measured and recorded to calculate volume, biomass, and carbon. This method uses "allometric equations" for each species. Allometric equation formulas calculate total above ground biomass by assigning the phenotypical relationships between varying physical tree components (U.S Forest Projects, 2015). Allometric equation coefficients are created at the individual tree level, however they can be expandable for an entire forest or region with an "expansion factor" $(\mathrm{k})$ (Brown, 2002). Allometric equations can be used for future calculations and they reduce the need for future field work once published (Ravindranath and Ostwald, 2007). The most limiting factor with allometric equations is that they are typically species specific, or provenance specific, so more field work is needed to develop equations that are accurate for each new tree species or new regions and they require extensive physical measurements in order to create the simple coefficients.

The data inventory method is extensively used not only to track changes in forests but also to monitor biodiversity and production of commercial timber (all above-ground biomass) (Kuyah et al., 2012). Allometric mathematical statements are a fundamental instrument for the non-destructive estimation of biomass in woody vegetation (Addo-Danso, Prescott, and Smith 2016). Therefore, these equations are effectively used to calculate biomass in terms of efficiency for time and labor. Allometric equations express tree biomass as a component of the parameters, for 
example, diameter, height, or wood density, or a combination of these (Kuyah et al., 2012). Diameter at breast height is commonly used for above-ground biomass (AGB) estimation because it is simple to be repeatedly measured with high accuracy, and generally follows commonly acknowledged forestry conventions (Kuyah et al., 2012). Nevertheless, the relationship between biomass and tree dimensions differs among species and may also be affected by site characteristics and climatic conditions (Kuyah et al., 2012). For example, crown area may be an important character for species with larger spreading crowns or tree species have different growth forms in northern or southern portions of their range. The standard form for above ground biomass forest allometric equations (Jenkins et al., 2003) is fitted as;

$\mathrm{Bm}=\operatorname{Exp}\left(\mathrm{B}_{0}+\mathrm{B}_{1} \ln D B H\right)$, Where; $\mathrm{Bm}=$ total above ground biomass $(\mathrm{kg})$ for trees 2.5 $\mathrm{cm} \mathrm{DBH}$ and larger, $\mathrm{DBH}=$ Diameter at breast height $(\mathrm{cm}), \mathrm{Exp}=$ Exponential function in excel, $\mathrm{Ln}=$ natural log base "e" (2.718282)

\subsubsection{Below-ground Biomass/Carbon}

Forest biomass contains approximately 7.2\% carbon below-ground (Peichl and Arain, 2007). Below-ground "live" refers to carbon in the coarse roots of live trees while carbon in the fine roots is included as part of the soil pool (Hoover and Rebain, 2011), but neither are reported here in FVS modeling and data inventory section. Below-ground biomass and carbon are the most expensive pools, in that they are the most complicated and difficult part of carbon pools to measure in the field requiring expansive labor and time. The tree that is assigned for below-ground measurements must be cut and dug up (destroyed) in order to reach its roots (Addo- 
Danso et al., 2016). Below-ground biomass can be estimated using the above-ground bole volume with allometric equations (U.S Forest Projects, 2015), which results in most below-ground biomass to be estimated as a portion of above-ground biomass (Ravindranath and Ostwald, 2007). Below ground biomass and carbon is not a focus of the study here, so further discussion will not include these estimations.

\subsubsection{Dead Organic Matter and Litter}

Biomass in deadwood and litter is contributes about $6.29 \%$ of the total carbon on average (Peichl and Arain, 2007). Litter and deadwood are an important issue when forest lands are converted to any other land use system (Ravindranath and Ostwald, 2007). Dead organic matter consists of deadwood (falling or standing) and leaf, small branch/twigs, litter on the forest floor. Deadwood can be either lying on the ground or partially decayed in the soil. It includes naturally dead trees, those killed by pest attack, wind damage, and harvesting practices, dead roots, and large stumps that are larger than $10 \mathrm{~cm}$. Litter is a layer of organic debris is a non-living biomass with a size of greater than $2 \mathrm{~mm}$ (the maximum limit for soil organic matter) and smaller than $10 \mathrm{~cm}$ (the minimum limit for deadwood). Litter is not one of the major carbon pools, as it includes woody and non-woody parts of trees and shrubs as they dry up and fall to the ground. Differentiation between deadwood and litter is only determined by its size (Ravindranath and Ostwald, 2007).

Gain-loss and stock-difference methods are used to calculate biomass in litter and deadwood. Gain-loss requires significant detailed effort for the annual transfer of biomass into litter and deadwood. The stock difference provides an easier way to 
calculate changes of all pools per year. Therefore, the stock difference is a recommended method for carbon calculation in litter and deadwood (Ravindranath and Ostwald, 2007), if resources are not available for data inventory. As in the previous section, there will not be further discussion for deadwood and litter as these pools are not the focus of this report but are mentioned here for integrity.

\subsubsection{Soil Organic Matter}

Soils include the largest carbon pool in the forest ecosystem. Forest ecosystems are the major pool for soil organic carbon which stores $70 \%$ of global soil organic carbon (Smith, Heath, and Nichols, 2007), and forest soils contain about 43\% of total carbon in forest ecosystem (Lorenz and Lal, 2010). Soil organic carbon is needed to be reported as one of the highest carbon pools. Calculating soil organic matter can be the most difficult component of estimating the amount of carbon in soil. It can be estimated by observing changes during the year. Stock difference is the recommended best approach for this carbon soil organic carbon pool (Aalde et al, 2006).

Soil organic carbon increases over time because all other materials such as dead woods, shrubs, litters, etc. are converted to soil (Lorenz and Lal, 2010). Therefore, stored carbon in forest soil fluctuates accordingly, mostly increasing over time, though the rate of this increase can change, especially when environmental conditions are altered, for example, due to climate change (Lorenz and Lal, 2010). No further discussion will follow with SOM carbon, as this is not the focus of this study. 


\subsection{Gain and Loss Estimation Methods}

Gain and loss method was developed for those countries who do not have their local methods to measure their stocked biomass and carbon. Gain refers to total aboveground and below ground biomass growth and loss refers to timber harvesting, and losses from fire, insect damage, illegal cutting, diseases or other disturbances resulting in mortality (Federici, 2011). Losses also affect below ground biomass because dead organic matter increases (Federici, 2011). This can be simple exchange between the carbon pools.

The formula for Gain-Loss is: $\Delta \mathrm{C}=\Delta \mathrm{CG}-\Delta \mathrm{CL}$

Where;

$\Delta \mathrm{C}=$ Annual carbon stock change in the pool, tonnes $\mathrm{C}$ yr-1

$\Delta \mathrm{CL}=$ Annual loss of carbon, tonnes $\mathrm{C}$ yr-1

$\Delta \mathrm{CG}=$ Annual gain of carbon, tonnes $\mathrm{C}$ yr-1 (Federici, 2011)

This formula is used for general gained and lost carbon, therefore there are no details about carbon pools or tree species, or which species store more than others, or which pools store more carbon than other pools. This is easy to apply and compare between reporting countries, but little detail information is available to inform policy. 


\subsection{Stock Difference}

There are two different ways to estimate stock changes (Federici, 2011).

a-) The process-based approach, which estimates the net balance of additions to and subtraction from a carbon stock. This approach allows us to determine emissions and removals over time, this mostly occurs as land use preferences change, such as harvesting. Harvesting is considered loss of carbon from the entire stock.

b) The stock-based approach, which estimates the difference in carbon stock at two times. It is usually a 5 -year cycle.

The formula for stock-difference carbon estimations is:

$\Delta \mathrm{C}=\left(\mathrm{C}_{2}-\mathrm{C}_{1}\right) /\left(\mathrm{t}_{2}-\mathrm{t}_{1}\right)$

Where:

$\Delta \mathrm{C}=$ Annual carbon stock change in the pool, tonnes $\mathrm{C}$ yr-1

$\mathrm{C}_{1}=$ Carbon stock in the pool at time $\mathrm{t}_{1}$, tonnes $\mathrm{C}$

$\mathrm{C}_{2}=$ Carbon stock in the pool at time $\mathrm{t}_{2}$, tonnes $\mathrm{C}$

In this approach we can determine how much carbon gained or lost from the previous time until now. For example; if we calculated carbon in 2013 and 2018 we can subtract or extract to see five-year changes. 


\subsection{Objectives and Goals}

The major goal of this project and manuscript was for me to become familiar with overall carbon policy for Turkey following Kyoto Protocol requirements, specifically with protocols for calculating forest carbon and biomass. The general objective was to prepare recommendations for Turkey regarding improving forest carbon measurements. The goal of this study is to compare Forest Vegetation Simulator (FVS) models to the manual method (data inventory method) by using the same data set, essentially evaluating the FVS model for the Turkish government to determine applicable methods and use efficiency in order to recommend what resources would be required to build a similar model for Turkey.

\section{Methods}

\subsection{Data Collection and Site Description}

Penobscot Experimental Forest (PEF), Maine was used for data collection as a study area to compare the carbon calculation methods. Penobscot Experimental Forest is in Bradley and Eddington, Maine. The PEF includes 1051 ha and was purchased by the University of Maine Foundation in 1995 (Morrill and Kimball, 2009). Species that were

observed in the field are typical of mixed northern hardwood forests in North America including paper birch (Betula papyrifera Marshall), white spruce (Picea glauca Moench (Voss)), red spruce (Picea rubens Sarg), eastern hemlock (Tsuga canadensis (L.) Carrière), red maple (Acer rubrum L.), white pine (Pinus strobus L), 
and balsam fir (Abies balsamea (L.) P. Mill). The entire PEF is covered by 13\% softwood, 19\% hardwood and $68 \%$ mixed forest. (Morrel and Kimball, 2009). These species are also major commercial species in Maine`s forest, especially balsam fir, pine, and spruce.

The PEF is an experimental forest land, and is mostly used for educational purposes, research, and for the training of students. Data was collected within a 7.3 meter (24-foot) radius plot, and starting from the north, all trees were recorded in a clockwise direction for data inventory method. Additional data were collected from Penobscot experimental forest (PEF) for FVS. The trees that were bigger than $10 \mathrm{~cm}(4.0$ inches) were measured in a plot circle. Once we were provided a plot location by FIA, we went into the field with crew members, including myself.

\subsection{Data Analysis}

I worked with the United States Department of Agriculture, Maine Forest Inventory and Analysis (FIA) program, collecting data in the summer of 2016. While FIA data was collected throughout the state, the data that I used for this study was collected in the Penobscot Experimental Forest (PEF). The plot center is usually identified by a tree, and this tree becomes the tree that was cut down to allow its measurements on the ground. The center tree is measured to determine the following components; height of the tree (HT), diameter at the breast height (DBH), crown width, tree species, status Live (L) or Dead (D), crown classes (CC) ( which are Dominant, Codominant, Intermediate, or Suppressed/overtopped), form of the tree (F), 
risk (R), height to crown base (HT_CR), height to the largest branch (HT_LGBR), and diameter of the largest branch (DIA_LGBR) (Pelletier et al., 2013). The center tree is cut, and it is separated from its branches without losing any of the pieces we put a large tarp on the ground before we cut the tree down. The stem is divided into parts based on its length. We generally separated three parts, with each part being about 4.96 meters (16.3 feet). The center tree is ready to cut down after this data has been recorded. The samples from the partitioned trees were taken in zipped plastic bags, and then taken to the laboratory to determine their moisture content. To determine the wood density, samples were taken from the lower, middle and upper parts of the stems. The samples were taken as a pie shape or cylinder, so the inner and outer parts of the trunks with their barks were included (Basuki et al., 2009). Appropriate number for these samples are taken basis of tree length and amount of dead wood and branches. Overall idea here is to bring enough data from field in to laboratory in order to build/create coefficients, these samples give us imagination how big this tree is because samples are taken from bottom to top and between these two parts. Dry weights were obtained by drying the samples at a temperature of $105 \mathrm{C}$ until a constant weight (generally 72 hours) was recorded (Basuki et al., 2009). The other trees within the plot sample were also measured; species, height of the tree, $\mathrm{DBH}$, alive or dead, crown classes.

The total study area includes 1.2949 hectares (3.2 acre) total area, with 549 trees that were measured DBH and species. Data was collected starting one point and measuring next trees by using diameter tape to measure $\mathrm{DBH}$, tree species were 
identified and these recorded trees were used in both FVS and manual calculations in excel to estimate total above-ground biomass and carbon. One tailed T- tests were used to compare total carbon estimation results from FVS and manual calculations. Other comparisons noted were the efficiency in skills, time, cost and labor needed for each method. Total biomass (Table 2) was designed to illustrate total above-ground biomass that is calculated in excel by using Jenkins` formula $(\mathrm{Bm}=\mathrm{Exp}$ $\left.\left(\mathrm{B}_{0}+\mathrm{B}_{1} \ln D B H\right)\right)$. Total trees and their individual biomass calculations were added as an appendix II at the end of study.

Table 2: Trees inventoried, their total biomass and mean diameter at breast height $(\mathrm{DBH})$ in Penobscot Experimental Forest (PEF) in Maine. Data was collected in summer 2016. Biomass (in tons) were calculated by using Jenkin`s equation for above ground biomass $\left(\mathrm{Bm}=\operatorname{Exp}\left(\mathrm{B}_{0}+\mathrm{B}_{1} \ln D B H\right)\right)$.

\begin{tabular}{|c|c|c|l|}
\hline Species & $\begin{array}{c}\mathrm{n} \\
\text { trees }\end{array}$ & $\begin{array}{c}\text { Mean of DBH } \\
(\mathrm{cm})\end{array}$ & Biomass(tons) \\
\hline Abies balsamea & 288 & 24.1 & 29120.2 \\
\hline Tsuga canadensis & 61 & 19.5 & 16079 \\
\hline Betula papyrifera & 25 & 23.1 & 8506.1 \\
\hline Acer rubrum & 81 & 25.5 & 9545.4 \\
\hline Picea rubens & 58 & 24.0 & 1829.6 \\
\hline Pinus strobus & 36 & 23.1 & 2919.7 \\
\hline Total & 549 & 25.3 & 68000 \\
\hline
\end{tabular}




\subsection{Data Preparation for allometric equations}

The tree species were measured in Penobscot Experimental Forest, counted a total of 549 trees in 1.2949 hectares (3.2 acre) total study area. The following preparations show how to calculate individual tree biomass. However, unfortunately I did not have enough samples to create my own equation, so I used created equations by Jenkins in 2003. Equation coefficients could be created with this many trees, but it would be very limited to the location and specific size of trees in this small of an area. Since this study was prepared as a guide to create new equations, following steps explain how to create a new allometric equation for individual tree species.

To create an allometric equation for each tree species, the tree that was identified to be in the middle of the plot was cut down and all green parts aboveground and dead/dried branches were weighed. Samples from the center tree were brought to the lab and dried in an oven until the constant weight was recorded. The diameter of the subject tree was measured at the breast height (DBH) to the top height of the tree (HT). Back in the plot, all trees were measured within a 24-foot (7,32 meter) radius of the center of the subject tree. Using the trees within 24 feet we could get an area-based estimate and expand out to an acre basis. On all plots, all trees over about $10 \mathrm{~cm}(4 ")$ were measured. We weighed the entire tree (above the stump), so we know actual green biomass, as we brought samples including the stem, bark, leaves, dead and green branches with a zip-lock plastic bag. This data inventory method (Method-1or manual 
calculations) also fits the design as a Jenkins' model to create allometric equations. Jenkins`coefficients were created for models and equations (Jenkins et al. 2003) were used in this project. Because Jenkins has already created an allometric equation for each species group of the United States common trees species.

Creating an allometric equation for individual tree species in order to estimate aboveground biomass as follows;

I. The tree was marked to cut it down, and entire tree wright (green weight) was measured in the field by using a weighing scale helping with forwarder machine.

II. Tree parts were separated from bottom of the stem (4.96 meters or 16.3 feet)

III. Disks were taken from bottom and top of each separated parts.

IV. After data collection was completed in the field, samples which are disks from stem, leaves, dead branches, species and dbh were brought into the office/lab, ready for measuring in detail.

V. Barks are removed from disks that are taken from bottom and top of the stem.

VI. Disks dimensions are measured, and put in the oven.

VII. Dry weight is measured by putting the samples in oven with $100^{\circ} \mathrm{C}$ $105^{\circ} \mathrm{C}$ and samples were weighted every day until the constant weight 
was observed (generally 72 hours- 3 days). Record dry weight until observing the constant weight.

VIII. Dry biomass was computed partially from the tree parts that we brought from field, and summed as the sum of all components weights (bole, branches, and foliage). Total dried weight is used as a reference number to figure out appropriate coefficients that provide us the observed dry biomass.

IX. Allometric equations are created based on a relationship with DBH and total tree biomass. The equation $\left(\mathrm{Bm}=\operatorname{Exp}\left(\mathrm{B}_{0}+\mathrm{B}_{1} \ln D B H\right)\right)$ is fit to data with biomass and dbh using linear regression.

$\mathrm{X}$. The logarithmic model form that is commonly used in biomass studies is used to create new coefficients.

XI. Next step is to determine the best model equations to fit with data in order to get calculated biomass. Some example models are as follows;

Model 1A: $\ln (\mathrm{Y})=\mathrm{B}_{0}+\mathrm{B}_{1} \ln (D B H)$

Model 1B: $\ln (\mathrm{Y})=\mathrm{B}_{0}+\mathrm{B}_{1} \ln (H)$

Model 1A: $\ln (\mathrm{Y})=\mathrm{B}_{0}+\mathrm{B}_{1} \ln (C W)$

Where $\ln =$ natural logarithm, $\mathrm{Y}$ the dry weight of the tree (above-ground biomass), $\mathrm{DBH}=$ diameter at breast height $(\mathrm{cm}), \mathrm{H}=$ total tree height, $\mathrm{CW}=$ crown 
width (m), and $B_{0}, B_{1}$ are parameter to be estimated. Model one was used with estimated Jenkins` parameters (Tumwebaze et al. 2013).

As a result of these steps; woody samples were taken in the laboratory to remove moisture content by using oven. Then dry biomass was recorded after removing moisture content. Since we know the dry biomass of an individual tree and its dbh, we use regression models to decide coefficients which should provide us dry weight that we already measured in office. What we have need to measure in the field are dbh, species, green weight, dry weight because we have $\mathrm{Bm}=$ total above ground biomass, $\operatorname{Exp}=$ exponential function in excel, $\ln =$ natural $\log , \mathrm{dbh}=$ diameter at breast height. $\mathrm{B}_{\mathrm{o}}$ and $\mathrm{B}_{1}$ were decided for individual tree species after enough data/samples (115 trees) were measured.

I followed the national scale requirements which are rules of data collection and processing for United States tree species under FIA requirements. Steps above will be used as how to create equations for each tree, but I used Jenkins' equation since it is current and common in U.S. One of my aims was to learn how to create these equations based on average tree morphology as I will be working in carbon and biomass calculation in Turkey. Steps above will be used to create or update equations of trees in Turkey.

Data was applied to Jenkins' model to get the amount of biomass of collected data. These steps are made to create coefficients of tree species, and have been made for trees in the U.S., however, many tree species and habitat types in Turkey do not have these coefficients. 


\subsection{Equations and Models}

I have chosen FVS and data inventory method to compare, as FVS is a readily available modeling tool and faster than most methods, does not require to cut a tree down, while both methods allow calculations of individual tree biomass and carbon. These two methods could be customizable for forests in Turkey improving the current carbon calculation system. The FVS program is also able to make applied carbon calculations directly in the program, projected into future stand conditions.

A data inventory (data inventory method) was used and formatted from Jenkins

model for allometric equations. Jenkins`equation were used in this study because it is an approved and highly used equation in U.S. Different results might be expected for future years between FVS results and manual calculations because FVS predicts mortality (completion or natural mortality as a lost carbon from above-ground carbon pool) and manual calculations use actual data. Therefore, there will definitely be differences basis of FVS future simulation accuracy, but not for immediate year calculations, and user`s accuracy.

\subsection{Method 1: The forest data inventory method}

Forest data inventory is the most effective and practical manner for estimating above-ground biomass and carbon, as the data is generally collected according to the process mandated by UNFCC (Brown, 2002). Manual data collection can be costly in 
the amount of time and labor spent collecting the data. A data inventory method was used as a potentially applied model potentially for Turkey, where data was collected for only living trees (of multiple species), and above ground biomass was calculated. Total carbon is being estimated to be 34000.0 tons for 549 trees. Total forest carbon was converted from total amount of biomass which is 6800.0 tons for entire study area 1.2949 hectares (3.2 acres), All calculations were conducted in excel with Jenkin`s. Parameters (Table $3\left(\beta_{0}, \beta_{1}\right)$ were applied onto my data shown below

Table 3: Above-ground biomass species coefficient/parameters for species that measured for this study (Jenkins et al. 2003).

\begin{tabular}{|l|l|l|}
\hline \multirow{2}{*}{\multicolumn{1}{|c|}{ Species }} & \multicolumn{2}{c|}{ Parameters } \\
\cline { 2 - 3 } & $\mathrm{B}_{0}$ & $\mathrm{~B}_{1}$ \\
\hline Abies balsamea & -2.5384 & 2.4814 \\
\hline Tsuga canadensis & -2.5384 & 2.4814 \\
\hline Betula papyrifera & -1.9123 & 2.3651 \\
\hline Acer rubrum & -1.9123 & 2.3651 \\
\hline Picea rubens & -2.0773 & 2.3323 \\
\hline Pinus strobus & -2.5356 & 2.4349 \\
\hline
\end{tabular}

\subsection{Method 2: Forest Vegetation Simulator (FVS)}

The Forest Vegetation Simulator was designed as the Stand Prognosis Model in the 1970s by the USDA Forest Service ("Forest Vegetation Simulator FVS," 2017), now available for download link https://www.fs.fed.us/fvs/software/complete.php. 
It has since been developed throughout the years, with additional modeling capabilities, and expanded species and regional best fit models to select from. FVS is used for estimating/calculating forest conditions for different purposes such as yield modeling, forest growth, and more (Hoover and Rebain, 2011). In this project, FVS was used as a reference model since it uses the same equations for carbon and biomass calculations. It is extensively used by forest managers and decision-making in the U.S because it visually and numerically demonstrates different management prescriptions before any intervention has been applied.

FVS has different variants of models based on locations (figure1), with different allometric equations for species, resulting in 20 variants in the U.S. (Luke, Douglas, 2015) For instance, the state of Maine uses the Northeast (NE) variant, but Michigan data users would select the Lake States (LS) variant. These variants are calibrated to a particular geographic area of United States. Users should select a correct variant for their area of interest. (Check for variants https://www.fs.fed.us/fvs/whatis/index.shtml)

To calculate carbon statistics in FVS, the acronym keyword is CARBSTAT. Carbon calculation keywords are designed to calculate the amount of carbon stored in various pools. This function is generated by the Fire Fuels Extension (FFE). The Fire and Fuel Extension (FFE) predicts fire behavior and its effects and gives us a carbon accounting report with each cycle year (5 years are included in this study). Argument 1: Code pointing the carbon pool, as follows 1 to 17 , and these codes may be applied separately if researchers are seeking carbon estimations. Example: the function 
CARBSTAT (9) turns back the total stand carbon in units contracted on the CARBCALC keyword record. (G. Dixon, 2013). "CarbCalc" was used and redesigned from "FFE" to "Jenkin`s and other".

Output options in FVS for specific carbon pools:

$1=$ Total above ground live tree carbon

$2=$ Merchantable above ground live tree carbon

$3=$ Below ground live carbon (roots)

$4=$ Below ground dead carbon (roots of dead or cut trees)

$5=$ Standing dead carbon

$6=$ Down dead wood carbon

$7=$ Forest floor carbon

$8=$ Shrub and herb carbon

$9=$ Total stand carbon

$10=$ Total removed carbon

$11=$ Carbon released from fire

$12=$ Merchantable removed carbon in wood products

$13=$ Merchantable removed carbon in landfills

$14=$ Merchantable removed carbon emitted with energy capture 
$15=$ Merchantable removed carbon emitted without energy capture

$16=$ Merchantable removed stored carbon (products + landfills)

$17=$ Merchantable removed carbon (all categories)

Forest vegetation simulator data preparation steps are as follow (figure 2)

Select data preparation on main menu

D Select Modify/Create Locations

$>$ 'Edit Locations File' menu will pop up

$>$ 'Location file' write a location name in the box "suppose.loc"

Select 'Edit records that define Locations Using Databases (Type C)'

> 'Location Name' "Database" or choice of user's preference

$>$ 'Data Source' "Select your data source on your computer" for example; "C:|FVSData|Blank-Database"

$>$ Finally click "Ok" (figure2)

FVS also is not quite simple without taking any courses or training. I have been taught a course called 'forest inventory and analyses for one semester. We mostly work with FVS for different silvicultural purposes such as "thin from below" and "thin from above". It is recommended to take some courses to work with FVS. Professional societies usually offer continuing education programs for technology.

To get final carbon report from FVS, select "add keywords" and click Fire and Fuel Extension, then go to category window (figure 3) select all keywords, and next 
click "CarbRept" and click accept to add this keyword in order o get an output report(figure3).

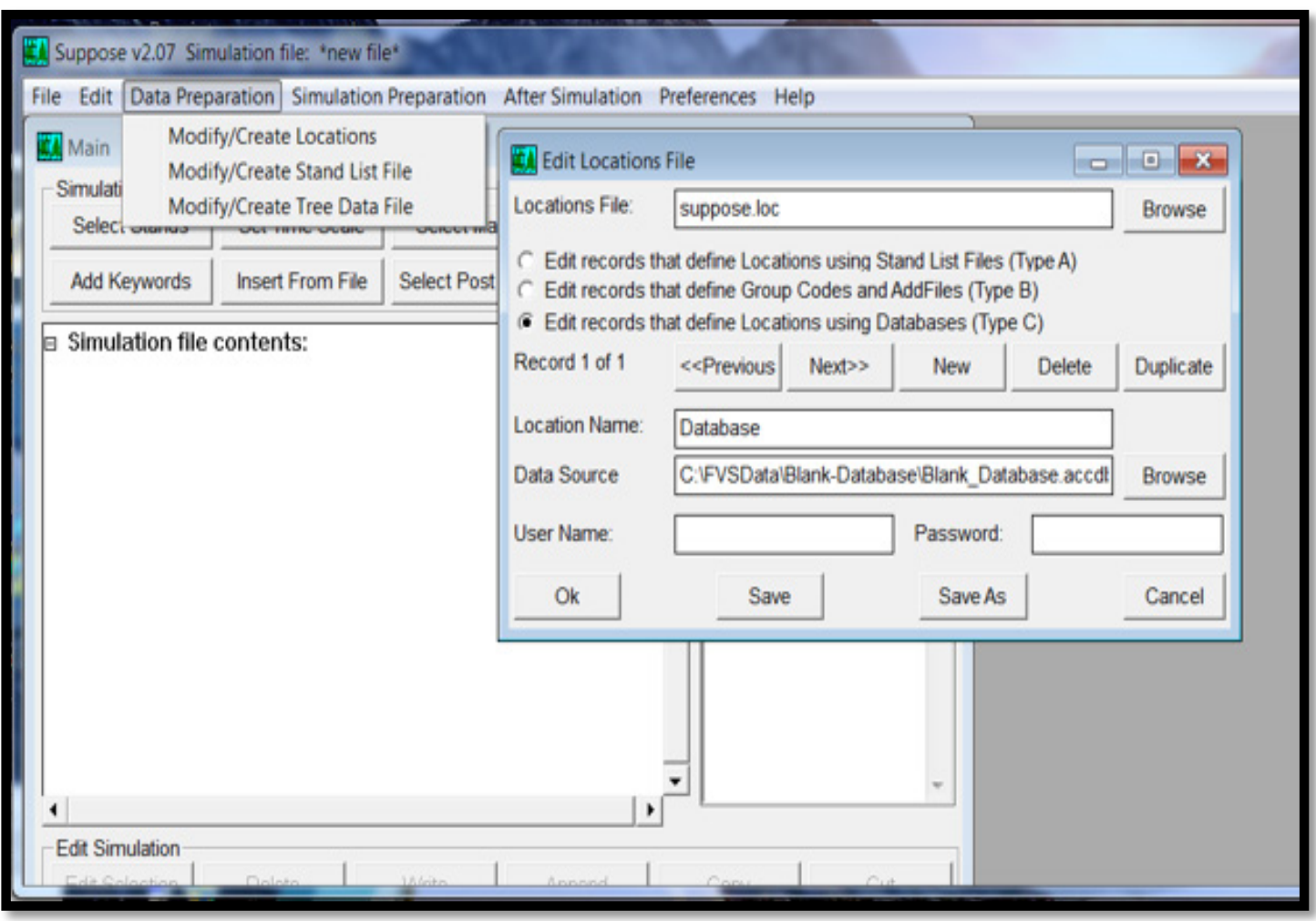

Figure 1: Forest Vegetation Simulator (FVS) data preparation steps; Data preparation $>$ Modify/Create Location $>$ "Edit Location File" $>$ Edit records that define Location Using Database (Type C) $>$ Location Name "Database"> Data Source "C/FVSData/Blank-Database.accd"

I have changed the default formula that was "FFE biomass predictions" to "Jenkin`s and others" from the page settings. FFE is other carbon calculation formula that was added in FVS more accurately estimating fuel load risk. Jenkins`s equations were used here in this study because manual calculations were also made with the same formula. Outputs for the both methods were not significantly different for the 
year data was collected. It is possible to see changes for future years because FVS was simulating trees for future while manual calculations are needed to update data by re-collecting data for next calculations. FVS also predicts mortality, growth, yielding, and regeneration therefore future results might show higher difference

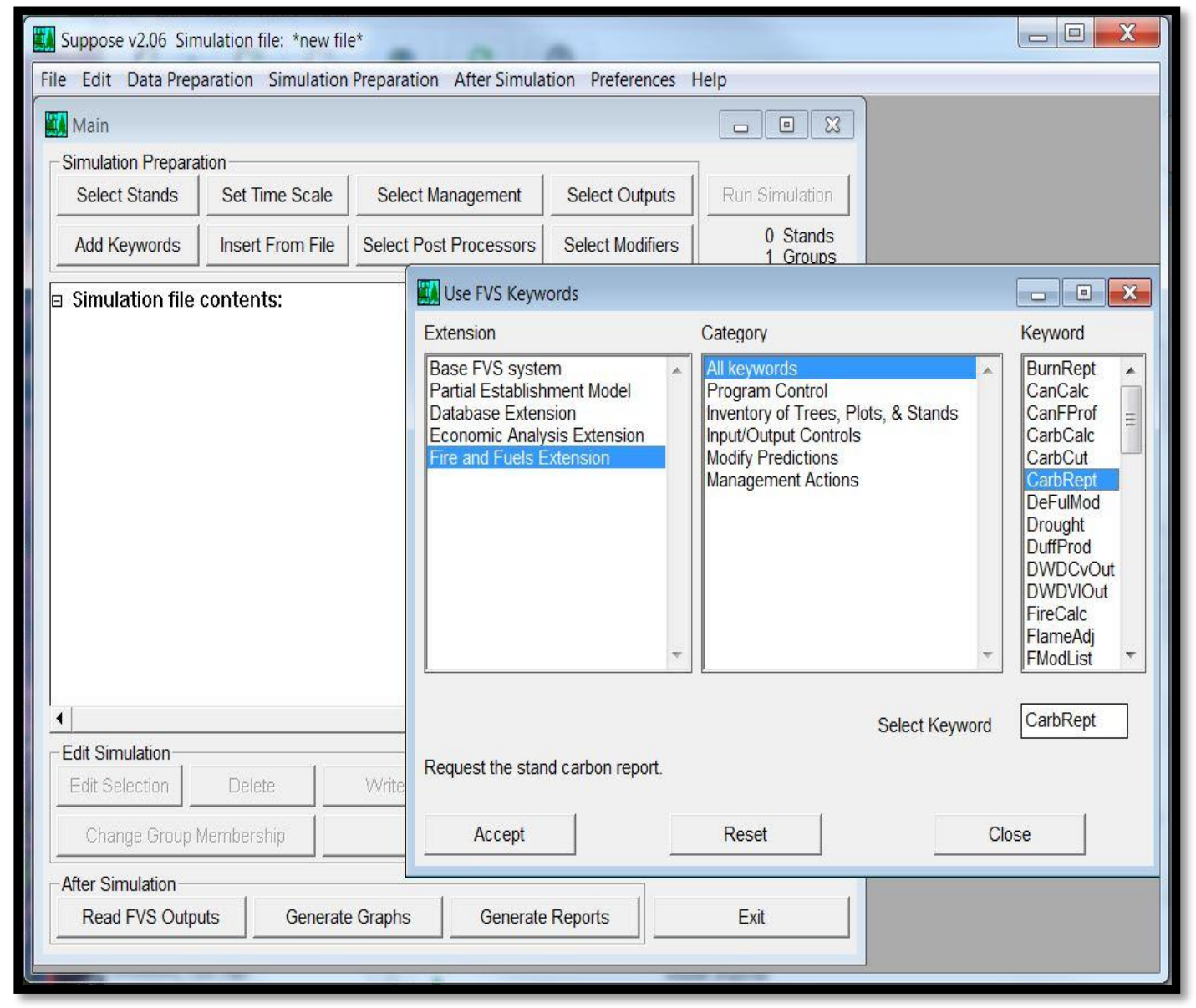

Figure 2: Forest Vegetation Simulator "CarbRept" keywords under Fire Fuel Extension (FFE) function, this tool is used to calculate above-ground carbon. Figure shows where this tool in FVS (Suppose v2.06, 2017).

It is also important to check how FVS was predicted before, and what it says now. For example figure 4 shows years start with 2016, we may consider to check FVS in 2021 to see what FVS told us 5 years ago (we assume we are in 2021 now), 
and what it is calculated now. It would be another project to test FVS accuracy with itself. Multiple versions and updates are regularly added to the FVS program as researchers new and more accurate models.

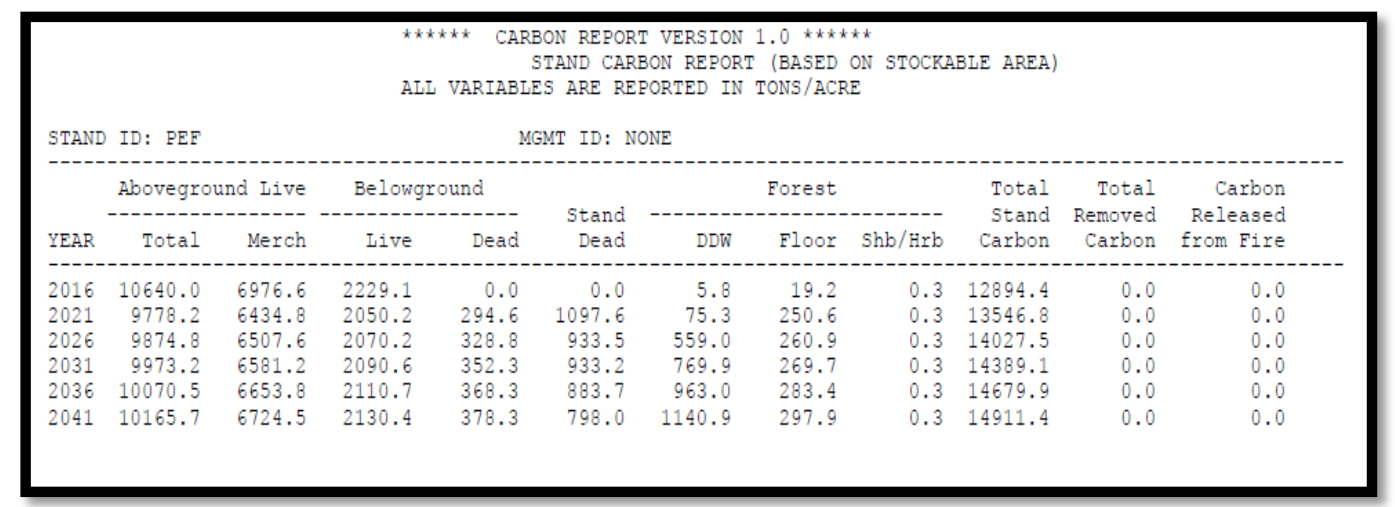

Figure 3: Forest Vegetation Simulator model carbon results include multiple carbon pools (FVS-Output Jenkins Equations) above-ground carbon was measured with fiveyear intervals started in year 2016. Data used here is from Penobscot Experimental Forest in Maine (2016).

In 2016, the total above-ground stand carbon is 10640.0 tons/acre stored as calculated by FVS. I have multiplied this amount by (3.2 acre) 1.2949 hectares which is study area that covered these trees. The total carbon for entire study site is 34048 tons for 1.2949 hectares (3.2 acre). According to FVS, the total amount of carbon slightly decreases, then increased through the years. I have chosen 5 years cycle length started from 2016 to 2031 . This stand will be gradually decreasing the stored carbon from 10640.0 to 9778.2 tons/hectare because of species competition or natural mortality. Some management suggestions for this stand may be considered to manage in terms of increasing the stored carbon. Thinning might be a good method to capture 
larger trees, it will provide some spaces for regeneration as well. We might observe increasing carbon if we an appropriate management plan is applied.

\section{Results and Discussion}

Both methods showed almost the same mathematical result for 2016. Output from FVS is 34048 tons for and manual calculations have come 34000 tons. This amount which is coming from FVS (34048 tans) is slightly higher than manual calculations, but the difference is not significant based on one tailed T-tests (with $p$ value $=1.95, \alpha=0.02$ ). These two results are for the year 2016 when data was collected, from this date results may not close to each other as this level (98\%) because FVS will simulate future growth and yield of forest basis of its capable, and manual calculations are made after data collection because trees will be gaining or losing the biomass as well as carbon. This study showed the FVS is easy to implement with training and makes accurate calculations of above ground biomass. I will lead design team to develop a new carbon calculation method for Turkey, which will resemble FVS, but we still need to collect several reference data and make several manual calculations to model individual tree coefficients for tree species in Turkey, following the steps to produce allometric equations described previously. Although, I have used FVS to calculate aboveground carbon, it has several additional functions, which would beneficial for Turkey's forest management, but will require collaboration with many other potentially surrounding countries with similar trees and climate regimes, foresters and researchers to provide input for the models. It is a huge task to create a computer program such as FVS, but this study will cover its biomass and 
carbon calculation section. It has been a great opportunity to learn the FVS model because Turkey needs to create a new model. The reason why we were sent as a Turkish sponsored student is to bring useful applications and methods into Turkey. In this study I have gained useful information while I am working carbon calculations. I hopefully will be applying these methods in Turkey in the near future.

A side by side comparison was made between FVS and the data inventory method of the strengths and weaknesses (Table 4), including ease of use, labor intensiveness, and skills required that a program would have to consider before implementing policy regarding these carbon estimation methods. These two methods are applicable and useful for different situations, for example while data inventory method is effective for individual tree or plot level, FVS is more efficient for stand level biomass and carbon calculations, so it may depend on the specific project which is more appropriate.

Obviously, FVS is faster than data inventory for forest carbon estimation in the U.S because data inventory requires field and lab work, thus more people are needed to be able to process the samples. To run FVS, one might need to take a training course, though it is user friendly enough for those who already know how to use it, but people who have not used FVS before may need to learn some steps such as data preparation, including understanding and interpreting output file. 
Table 4: Comparison between two methods of carbon calculations; Forest vegetation simulator modeling and data inventory method (manual allometric equation for each tree) based on their use and efficiency in order to make recommendation for carbon forest management in Turkey.

\begin{tabular}{|c|c|c|}
\hline Methods & Strengths & Weaknesses \\
\hline $\begin{array}{l}\text { Forest Vegetation } \\
\text { Simulator(FVS) } \\
\text { (modeling } \\
\text { method) }\end{array}$ & $\begin{array}{l}\text {-allow/simulate many } \\
\text { varieties, before anything } \\
\text { has happened in real time } \\
\text {-can be calculated faster } \\
\text { than field work } \\
\text {-prepares reports; printable } \\
\text {-is it cost effective to } \\
\text { obtain program that } \\
\text { multiple people can use? } \\
\text {-can be calculated by a } \\
\text { single person if they have } \\
\text { access to input data }\end{array}$ & $\begin{array}{l}\text {-dependent to sample data } \\
\text { inventory, can`t stand alone } \\
\text {-needs training to be able to } \\
\text { use } \\
\text {-can`t predict real conditions; } \\
\text { just knows what you entered } \\
\text { - cannot use the same data if } \\
\text { there is mortality or insect } \\
\text { damage over the expected } \\
\text { percentage, so need to } \\
\text { sample again } \\
\text {-does not currently exist for } \\
\text { Turkey }\end{array}$ \\
\hline $\begin{array}{l}\text { Data Inventory } \\
\text { (manual method) }\end{array}$ & $\begin{array}{l}\text {-detailed measurements in } \\
\text { field and lab required } \\
\text {-re-measurements provide } \\
\text { comparisons with previous } \\
\text { conditions } \\
\text {-detailed results, such as } \\
\text { which pool stores how } \\
\text { much carbon } \\
\text { - Expand the data from the } \\
\text { plot level to the stand level } \\
\text {-individual tree species can } \\
\text { be traded based on their } \\
\text { carbon storage capacity }\end{array}$ & $\begin{array}{l}\text {-time-consuming } \\
\text {-extensive field and lab work } \\
\text { is necessary } \\
\text {-many technician skills are } \\
\text { needed, for example, } \\
\text { chainsaw, tape, GPS, etc. } \\
\text {-requires math skills } \\
\text { sensitive to human error } \\
\text {-may not be predictable for } \\
\text { successive management } \\
\text { plans; must address the right } \\
\text { methods, otherwise the study } \\
\text { will fail (not predictable) } \\
\text { - Requires group work } \\
\text {-still need coefficients } \\
\text { created and collecting dbh } \\
\text { and species data }\end{array}$ \\
\hline
\end{tabular}

It is also important to interpolate the results and understand how FVS processing the input data (table 4). Using the model would be more inefficient 
without some training or initial guidance as it would take longer to understand the parameters and outputs. In addition, we do not need to measure trees every year using FVS, as it is able to produce/simulate growth patterns on the basis of natural growth rate so to produce a projecting model in Turkey would require natural growth rate and harvesting information. This will not significantly affect the stored carbon level because when we consider the entire stand, FVS is sufficient for estimating yields for future years. Data inventory method and FVS provided carbon result values that are close to each other. Since these two methods use the same equation results still might be different because FVS do not take into account all trees while processing the equations. It simulates a stand based on inventory plot size which is 1.2949 hectares (3.2 acres) in this study. We might consider developing a similar program to FVS for five years carbon report requirements to IPCC, however we still need to use data inventory method either to collect data for trees it is still missing for or updating coefficients for provenance if needed.

This study showed that FVS and manual calculations are needed basis of their ability. The strongest point for FVS is to be able to simulate future condition without recollecting data and harvesting any trees. On the other hand, manual data inventory is still needed to update both equations and coefficients. Both method can be considered to use at the same time with different study area in Turkey because there are 7.8 hectares protected areas which should not be harvested. These areas must be measured kindly to collect dbh since these areas have biomass and carbon. 


\subsection{Recommendations for forests in Turkey}

Forests in Turkey are government owned with only $1 \%$ of forests on private land (Orman and Raporu, 2006). Due to this, forest management and protection is harder than in other countries, in which forests are owned by private land-owners (this is true in the United States, especially in Maine, where $94 \%$ of forests are privately owned). In Turkey, forests have slightly increased in the last few decades, and currently cover 30\% of land base (Orman and Raporu, 2006). Forests covered 60-70\% of land about 90-100 years ago, but significant deforestation occurred due to overgrazing, alterations of agricultural areas, fires, and illegal cutting by the public (Orman and Raporu, 2006). These obstacles indicate that forest management requires more attention to be able to protect and increase forests in Turkey (Academy, 2016). As with most countries, Turkey is required to report its amount of carbon to the IPCC. Therefore, Turkey needs more detailed investigation for current forest measurements to be able to clearly report the amount of carbon. Turkey uses two general methods: gain-loss and stock differences, but these methods are not clear or detailed enough for each tree species in Turkey. These two common methods were created by the Intergovernmental Panel on Climate Change (IPCC, 2007) for countries which do not have local methods. The recommendation to develop a FVS type program will help us to compare species based on their capability for carbon storage, and we can prepare new management plans or increase the amount of forest with the most capable species. Most of the trees in Turkey do not have any regional or species specific allometric equations, yet the U.S has several different methods varying by 
species, region or state, such as FVS. While these are several methods to calculate biomass and carbon in forests such as harvest methods, carbon flux measurements, satellite/remote sensing, modeling, plotless method (Ravindranath and Ostwald, 2007), this study includes an example of calculations and results by using coefficients to calculate biomass and carbon. These are the most time and cost efficient methods. Since most major tree species genera are similar with trees in U.S. (e.g. Pinus spp, Picea spp, Fagus spp, Quercus spp, etc.), this study provides comparable proofs that we can benefit by creating allometric equation for trees in Turkey. This saves time and money because we are quite certain that these equations are doing adequate calculations because of how allometric equations are created to get exact biomass for single tree species. It does not require to cut any species in the future so there is no need to cut trees every time to calculate biomass and carbon. The resources that are needed to build a FVS type program are intensive data collection, money, time, group of researchers who are expert in forestry. To create a FVS typ program is not easy, its complexity will take time. We should collect and analyze intensive data in order to create a FVS type simulation program. We luckily have an example that works fine in U.S. There are some advantages of coming from back from other countries, as it allows us to see the best methods in use rather than trying to find the best way through trial and error on our own. 


\subsection{Future Work}

My first task will be data inventory and creating equations for every important and most common species in Turkey. Then, I will suggest them to create a computerbased model similar with FVS because FVS works well for huge forest lands and it predicts future carbon stocks Data collection and creating coefficients is primary target to create allometric equations for each species in Turkey, and FVS is secondary to apply to forest management in Turkey. I hope to apply skills learned and redesign these methods in biomass and carbon calculations for forests in Turkey. I will start by collecting data in order to create new allometric equations for each species across the Turkey for important species that are missing coefficients. These coefficients will depend on climatic conditions, elevation, and soil structure. As a result of this study, Turkey will soon have new allometric equations and a computer-based model like FVS providing forest managers more detailed information to improve forest land decisions.

\section{Conclusion}

The greenhouse gasses from atmosphere will be decreased if every country follows the Kyoto Protocol policies about biomass and carbon. The methods discussed here in this section allow us to observe stored carbon, but we might additionally increase stored carbon by using appropriate management plans. Therefore, it is important to know the capacity of every species to see how they differ from each other. Turkey has a chance to increase forested areas because current land 
is available to increase forested areas. In this perspective, we might consider planting species which has higher capacity to store carbon. The main idea to reduce greenhouse gasses is by increasing stored carbon. We might reconsider forest management plans based on our targets, such as carbon level or lumber prices. Many people think that there will be a carbon market in the near future, with countries getting paid or charged based on the stored greenhouse gasses.

This study explains carbon pools and calculations for those who many not be familiar with them. The data inventory method has five aspects; above -ground, below-ground, litter, deadwood, and soil organic carbon (Federici, 2011). These components require detailed field and lab work to calculate the amount of carbon and biomass. On the other hand, the modeling method (using Forest Vegetation Simulator in this example) uses data that has already been collected in the field for data inventory method calculations. Hence FVS is a faster method than the data inventory method. However, FVS requires field inventory and some stand information, so data for both FVS and the data inventory methods can be gathered when we go to the field. FVS can simulate treatments for silviculture in most forest types and species and it allows us graphical simulations as a visual output. We can also customize FVS based on our purposes. On the other hand, the data inventory method requires significant field work and lab.

As a result, this work has explained two common methods besides manual and FVS. Each of these methods are adequate and has its own strong points. The amount of carbon and biomass stored in a forest provides excellent information to help 
formulate precise management plans. These calculations will also help to determine the best methodology for managing forests and calculating biomass and carbon in Turkey. Turkey is currently preparing and planning to apply biomass and carbon inventory methods to forest management systems. However, there are significant gaps in carbon and biomass calculations in Turkey. I will only be working on allometric equations for most common tree species which are Quercus spp (26.34\%) Pinus brutia (25.11\%) Pinus nigra (19\%) Fagus spp (8.5 \%) Pinus sylvestiris (6.80 \%) and other species such as Picea spp, Abies spp, Poplar or Populus spp, Castanea spp (Sonmez, 2015).

Most countries use the two most common methods indicated previously, but these methods are not as detailed and ease of use as FVS and the data inventory methods. FVS was provided satisfactory result that we may create and use a model such as FVS in Turkey. Currently, there is no clear evidence to support the usefulness of one method over another when it comes to preparing management plans. This is where we can use FVS to see possible management plans and their effects on forest, and we can decide the most applicable management prescriptions. It is a more efficient way to have an idea in the office before doing nothing in the field. 


\section{References}

Aalde, Harald, Patrick Gonsalez, Michael Gytarsky, Thelma Krug, Werner A. Kurz, Rodel D. Lasco, Daniel L. Martino, 2006. Forest Land. 2006 IPCC Guidelines for National Greenhouse Gas Inventories. Vol. 4. Doi:10.1016/j.phrs.2011.03.002.

Addo-Danso, S. D., Prescott, C. E., and Smith, A. R. (2016). Methods for estimating root biomass and production in forest and woodland ecosystem carbon studies: A review. Forest Ecology and Management, 359, 332-351.

Doi: 10.1016/j.foreco.2015.08.015

Amin, Malik, and Aslam Khan. 2010. Türkiye 'nin Ormanc1lık Sektörü ve Karbon Piyasası Raporu.

Basuki, T. M., van Laake, P. E., Skidmore, A. K., and Hussin, Y. A. (2009). Allometric equations for estimating the above-ground biomass in tropical lowland Dipterocarp forests. Forest Ecology and Management 257:1684-1694. Doi:10.1016/j.foreco.2009.01.027

Baskent, E. Z., Köse, S., \& Keles, S. (2011). Turkey’s Forest Management Planning System : How To Move Towards the Sustainable Management of. Africa, 1990, $1-6$. 
Brown, S. (2002). Measuring carbon in forests: Current status and future challenges. In Environmental Pollution 116: 363-372. Doi: 10.1016/S02697491(01)00212-3

Boisson de Chazournes 2008. United Nations framework convention on climate change. Doi: 10.1111/j.1467-9388. 1992. Tb00046.x, 1-7

California Environmental Protection Agency. Air Resources Board, 2015. 1-141 https://ww2.arb.ca.gov/

Carbon Pools and Measurement Frequency for Carbon Inventory. In: Carbon Inventory Methods Handbook for Greenhouse Gas Inventory, Carbon Mitigation and Roundwood Production Projects. Advances in Global Change Research, vol 29. Springer, Dordrecht, (2008). Doi:10.1007/978-1-4020-65477_4

Çolak, Alper H., and Ian D. Rotherham. A Review of The Forest Vegetation of Turkey: It's Status Past and Present and Its Future Conservation. Biology and Environment: Proceedings of the Royal Irish Academy 106B, no. 3 (2006): 343-54.

Dixon, G. 2013. Essential FVS: A User's Guide to the Forest Vegetation Simulator, no. January: 226. Doi: 10.1007/978-3-319-23883-8.

Dixon, G., and Keyser, C. (2017). Northeast (NE) Variant Overview Forest Vegetation Simulator. 
Downie, Adriana, David Lau, Annette Cowie, and Paul Munroe. 2014. Approaches to Greenhouse Gas Accounting Methods for Biomass Carbon. Biomass and Bioenergy 60. Elsevier Ltd: 18-31. Doi:10.1016/j.biombioe.2013.11.009.

Fahey, Timothy J., Peter B. Woodbury, John J. Battles, Christine L. Goodale, Steven P. Hamburg, Scott V. Ollinger, and Christopher W. Woodall. "Forest carbon storage: ecology, management, and policy." Frontiers in Ecology and the Environment 8, no. 5 (2010): 245-252.

Forest Inventory and Analysis National Program https://www.fia.fs.fed.us, 2017.

García Morote, F. A., López Serrano, F. R., Andrés, M., Rubio, E., González Jiménez, J. L., and de las Heras, J. (2012). Allometries, biomass stocks and biomass allocation in the thermophilic Spanish juniper woodlands of Southern Spain. Forest Ecology and Management. Volume 270, Pages 85-93.

Doi:10.1016/j.foreco.2012.01.007

Hoover, Coeli M.; Rebain, Stephanie A. 2011. Forest carbon estimation using the Forest Vegetation Simulator: Seven things you need to know. Gen. Tech. Rep. NRS-77. Newtown Square, PA: U.S. Department of Agriculture, Forest Service, Northern Research Station. 16 p.

Hoover, C, and S Rebain. 2008. The Kane Experimental Forest Carbon Inventory: Carbon Reporting with FVS. Carbon, 17-22. 
Jenkins, Jennifer C., David C. Chojnacky, Linda S. Heath, and Richard A. Birdsey, 2003. National-Scale Biomass Estimators for United States Tree Species. Forest Science 49 (1): 12-35.

Jenkins, Jennifer C., David C. Chojnacky, Linda S. Heath, and Richard A. Birdsey. "Comprehensive database of diameter-based biomass regressions for North American tree species." Gen. Tech. Rep. NE-319. Newtown Square, PA: US Department of Agriculture, Forest Service, Northeastern Research Station. 45 p.[1 CD-ROM]. 319 (2004).

Kuyah, S., Dietz, J., Muthuri, C., Jamnadass, R., Mwangi, P., Coe, R., and Neufeldt, H. (2012). Allometric equations for estimating biomass in agricultural landscapes: I. Aboveground biomass. Agriculture, Ecosystems and Environment. Doi: 10.1007/s00468-014-0993-2.

Lorenz, Klaus, and Rattan Lal. Carbon sequestration in forest ecosystems. Springer Science \& Business Media, 2009. Doi:10.1007/978-90-481-3266-9.

Morrill, Richard, and Alan Kimball. 2009. Penobscot Experimental Forest Forest Management Plan University of Maine Foundation Ownership University Forests Management Area. Research Policy, 1-8.

Miles, Patrick D. 2008. Forest inventory and analysis data for FVS modelers. In: Havis, Robert N.; Crookston, Nicholas L., comps. 2008. Third Forest Vegetation Simulator Conference; 2007 February 13-15; Fort Collins, CO. Proceedings 
RMRS-P-54. Fort Collins, CO: U.S. Department of Agriculture, Forest Service, Rocky Mountain Research Station. p. 125-129

Orman, Sürdürülebilir, and Yönetimi Raporu. 2006. Orman Genel Müdürlüğü

Sürdürülebilir Orman Yönetimi Kriter ve Göstergeler 2006 Yili Raporu, 190.

PEF management plan:(Morrill and Kimball 2009) Penobscot Experimental Forest, Forest Management Plan, University of Maine Foundation Ownership University Forests Management Area; 1-78

Peichl, M., and Arain, M. A. (2007). Allometry and partitioning of above- and belowground tree biomass in an age-sequence of white pine forests. Forest Ecology and Management, 253(1-3):68-80. Doi:10.1016/j.foreco.2007.07.003

Pelletier, G., de Graaf, M., Marcel Cyr, P., Labelle, E. R., Soucy, M., and Nyland, R. (2013). A Tree Classification System For New Brunswick Adapted from A Tree Classification System for New Brunswick, Gaetan Pelletier, 2012 Project Manager and Classification System Development.

Ravindranath, N.H., and M. Ostwald. 2010. "Methods for Estimating Soil Organic Carbon." Carbon Inventory Methods: Handbook for Greenouse Gas Inventory, Carbon Mitigation and Roundwood Production Projects, no.165-80. Doi: 10.1007/978-1-4020-6547-7_13

Saket, M. 2001. Wood volume and woody biomass. Global Forest Resources Assessment 2000, (July), pages 17-22. 
Sandro, 2011. General Methods for Estimating Stock Changes in Carbon Pools,

Smith, James E., Linda S. Heath, and Michael C. Nichols. 2007. U.S. forest carbon calculation tool: forest-land carbon stocks and net annual stock exchange. https://purl.fdlp.gov/GPO/gpo87694.

Su, Orman and Orman Genel. 2015. Orman Varliği 2015.

Thenkabail, P. S., Stucky, N., Griscom, B. W., Ashton, M. S., Diels, J., van der Meer, B., and Enclona, E. (2004). Biomass estimations and carbon stock calculations in the oil palm plantations of African derived savannas using IKONOS data. International Journal of Remote Sensing. 25:23, 5447-5472. Doi: $10.1080 / 01431160412331291279$

Tumwebaze, S.B., Bevilacqua, E., Briggs, R. et al. Agroforest Syst (2013) 87: 781. Doi.org/10.1007/s10457-013-9596-y

Tolunay, Doğanay. 2011. Total Carbon Stocks and Carbon Accumulation in Living Tree Biomass in Forest Ecosystems of Turkey 35: 265-79. Doi:10.3906/tar 0909-369. 


\section{Appendix I}

Previous studies that have had coefficients for tree species in Turkey are listed here.

> Pinus sylvestris L. (Uğurlu et al. 1976 (Stebe geciş yorelerindeki sarıcam

meşcerelerinde biyolojik kutlenin saptanması).

$>$ Pinus sylvestris L. (Atmaca, 2008 (Erzurum Orman Bolge Mudurluğu

Sarıcam Biyokutle Tablolarının Duzenlenmesi).

Pinus sylvestris L. (Çömez, 2010(Sündiken Dağlarında Sarıçam

Meşcerelerinde Karbon Birikiminin Belirlenmesi).

Pinus sylvestris L. (Tolunay, 2010 (Biomass factors and equations for the young trees (Pinus sylvestris L.) in northwestern Turkey).

$>$ Pinus brutia Ten. (Sun et al. 1980 (Kızılcam turune ait biyolojik kutlenin saptanmas1); Ünsal, 2007 (Adana Orman Bolge Mudurluğu Karaisalı Orman İşletme Mudurluğu Kızılcam Biyokutle Tablolarının Duzenlenmesi).

$>$ Picea orientalis (L.) Link (Özkaya, 2004(Artvin-Genya Dağı Yoresi Doğu

Ladini Ormanlarında Toprak Ustu BiyokutleninBelirlenmesi ).

> Pinus nigra Arnold (Çakı1l, 2008). (Zonguldak Orman Bolge Mudurluğu

Karacam Biyokutle Tablolarının Duzenlenmesi).

Fagus orientalis Lipsky (Saraçoğlu, 1998 (Kayın biyokutle tabloları). 
$>$ Alnus glutinosa (L.) Gaertn. (Saraçoğlu, 2000 (Sakallı Kızılağac biyokutle tablolar1).

> Quercus spp. (Durkaya, 1998), (Zonguldak Orman Bolge Mudurluğu Meşe Meşcerelerinin Biyokutle Tablolarının Duzenlenmesi).

> Castanea sativa Mill. (İkinci, 2000). (Zonguldak Orman Bolge Mudurluğu Kestane Meşcerelerinin Biyokutle Tablolarının Duzenlenmesi). 